\title{
Novidades no Tratamento da TVP
}

\author{
Maffei FHA. ${ }^{1}$ \\ ${ }^{1}$ São Paulo - Brasil. \\ E-mail:fmaffei@fmb.unesp.br
}

Maffel, F.H.A. 2013. Novidades no Tratamento da TVP, p.70. In: Bastos, Francisco Reis. Anais do V Simpósio Internacional de Flebologia [Blucher Medical Proceedings n.1 v.1]. São Paulo: Blucher, 2014

http://dx.doi.org/10.5151/medpro-flebo-SIF_43
O tratamento da trombose venosa profunda (TVP), embora bem estabelecido há anos, vem sofrendo aperfeiçoamentos e modificações visando aumentar sua eficácia, segurança, qualidade de vida do paciente e facilitar seu manuseio. Essas modificações basearam-se inicialmente na prática clínica e, mais recentemente, principalmente em ensaios clínicos controlados e metanálises com grande número de pacientes. No tratamento inicial, surgiu o encurtamento do tempo de heparinização, depois a utilização das heparinas de baixo peso molecular, seguida pela do fondaparinux, que diminuíram o número de injeções e a necessidade de controle laboratorial. Mais recentemente surgiu a possibilidade de substituir a via parenteral pela oral, com a rivaroxabana. Para casos muito selecionados de trombose íliofemoral, surgiu a possibilidade de complementação da fibrinólise farmacológica pela trombólise mecânica. No tratamento a longo prazo, houve uma melhora na determinação do tempo de anticoagulação, baseado no tipo de TVP e em exames auxiliares. O controle laboratorial dos antagonistas da vitamina $\mathrm{K}$ pode ser simplificado com o uso dos equipamentos tipo "point of care" e mais ainda com a utilização de anticoagulantes que não necessitam desse controle, como a rivaroxabana. Foi também comprovada a necessidade de utilização de meias elásticas, visando a prevenção da síndrome pós-trombótica.

Palavras-chave: TVP, trombose, trombofilia. 